\title{
Complex Behavior Characteristics of the Ground Under Multi-Pressed in Pipes for Non-Open Cut Construction by Laboratory Tests
}

\author{
Park SungBum ${ }^{1}, \mathrm{Kim}_{\text {YoungMin }}{ }^{2}, \mathrm{Kim} \mathrm{MiNa}^{3}$, Cho KookHwan ${ }^{4}$ \\ 1,2,3,4 Department of Railway Construction Engineering, Graduate School of Railway, \\ Seoul National University of Science \& Technology, South Korea
}

\begin{abstract}
For the substructure construction underpass railway or highway, a non-open cut method is applied for continuous running of vehicles and trains. This is used because non-open cut method does not require the installation of a separate detour road and relocation of existing structure or obstruction. The main concept of the non-open cut method is with a press-fitting steel pipe, of which diameter is 0.8 to 2.0 meters into the ground underneath traffic roads. However, the stress conditions such as earth pressures are changed and deformation of soil mass is occurred. This causes settlements at surface around the construction area, while several steel pipes are press-fitted into the ground. Therefore, it is necessary to develop a method that can minimize the stress release zone and maintain the stress equilibrium state of the ground. In this study, the calibration chamber tests were conducted to study ground deformation characteristics according to the complex behavior of press-fitted steel pipes used for non-open cut method. The results of the calibration chamber test indicate that the settlement due to the complex behavior of press-fitted steel pipes should be considered when using non-open cut method.
\end{abstract}

Keywords: complex behavior of steel pipes, ground deformation characteristics, non-open cut method.

\section{Introduction}

Subsurface constructions can be classified into two methods, which are open cut method and non-open cut method. Open cut method can cause problems such as traffic jams and relocation expenses of existing obstruction. Therefore, the use of non-open cut method has gradually increased for subsurface structure construction underneath railways and roads. This is because non-open cut method does not require the installation of a separate detour road and relocation of existing structure or obstruction. The main concept of non-open cut method is to press the steel pipe with a hydraulic jack, which is followed by contraction of the gravel from the inside of the steel pipe to the outside. This is performed with manpower and equipment. The steel pipe can be grouted both inside and outside, or reinforced it with steel or mortar if necessary.

Eum et al. [1] analyzed the ground behaviors on crossing construction under railways, using a front-jacking method and a pipe-roof method through field measurements. The results of the analysis indicated that more than $80 \%$ settlement occurred in steel pipe press-fitting processes.

Roh [2] analyzed the substructure construction underpass railway or highway by Roof Panel Shield (RPS) method using three-dimensional numerical analysis. The numerical analysis shows that $1 / 3$ of the final displacements occurred at the formation of steel pipe loop.

Choi et al. [3] analyzed settlements of the ground around the steel pipes by using three-dimensional numerical analysis. This showed that the vertical settlement is much larger than the horizontal displacement during the penetration of square steel pipes, and the settlement is also increased with decreasing the soil depth at the top of subsurface structure. 
Eum et al. [4] compared settlements and/or heaving of the ground in relation to the shape of pipes in the laboratory. The results indicated that the displacement during pipe penetration is more dependent on the penetration depth than the shape of the pipe, although the square steel pipe generates a little more heaving and/or settlement than the round shape at the same depth.

Kim et al. [5] analyzed the characteristics of stress release zones according to the diameter of steel pipes by using non-open cut method. The results from numerical analysis showed that the characteristics of displacements and shear stresses generated in the ground around constructed structure have linear relationship between pressfitted steel pipe diameters. The smaller diameter of press-fitted pipes, the smaller are the stresses generated during construction while using non-open cut method.

The non-open cut method is usually selected for the cases where safety or serviceability on the ground above subsurface structure being constructed is considerably important. Therefore, the behavior of groundmass around press-fitted pipes should be well thought through during construction.

In this paper, the ground deformation characteristics according to the complex behavior of steel pipes are investigated through the calibration chamber tests. The calibration chamber tests are carried out by varying the number of press-fitted steel pipes, and by soil depth/pipe diameters (H/D). The settlements of the upper ground are analyzed through these results.

\section{Stress Release of Excavation Ground}

The non-open cut method was developed in the concept that when the ground is excavated like a tunnel, the displacement of the upper ground is controlled by the pre-press-fitted steel pipe structure. Therefore, the purpose of this section is to summarize the method of predicting the release load of surrounding ground and the upper settlement during shallow tunnel excavation.

\subsection{Tunnels Through Sand of Terzaghi}

Fig.1(a) shows a section through a bed of sand in which a tunnel is being constructed between the horizontal surface of the bed and the water table. The cohesion of the Band is assumed to be not in excess of the feeble bond produced by a trace of moisture. Yet from experience we know that this trace of cohesion is sufficient to maintain the working face in small drifts without lateral support. Part of the yield of the sand toward the tunnel occurs while the working face passes the section shown in the figure and the remainder takes place after the timbering has been constructed. Owing to the imperfect fit of the timbers at the joints and the compressibility of the supports of the footings of the vertical posts, the yield of the timbering is usually sufficient to reduce the pressure of the sand on the timbering almost to the value corresponding to the state of incipient shear failure in the sand. This state is similar to the state of stress in a mass of sand above a yielding strip. The sand adjoining the sides of the tunnel also subsides on account of the yield of its lateral support. The inclined boundaries of the zone of subsidence rise at an angle of about $45^{\circ}+\Phi / 2$. Therefore, at the level of the roof of the tunnel, the width of the yielding strip is approximately equal to

$$
2 B_{1}=2\left\lfloor B_{0}+H \tan \left(45^{\circ}-\frac{\Phi}{2}\right)\right]
$$

It will be assumed that the potential surfaces of sliding through the outer edges of the yielding strip $b_{1} b_{1}$ are vertical. On this assumption the vertical pressure on the horizontal section $b_{1} b_{1}$ (Fig.1(a)) with a width $2 B_{1}$ is determined by $\mathrm{c}=0, \mathrm{q}=0$. We obtain.

$$
\sigma_{v}=\frac{\gamma E_{1}}{K \tan \phi}\left(1-e^{-K \tan \phi D / B_{1}}\right)
$$

Per unit of area of the horizontal section $b_{1} b_{1}$. In this equation the symbol $K$ designates an empirical coefficient. From the results of direct measurements, it has been found that the value of this coefficient is approximately unity. On both sides of the tunnel the pressure $\sigma_{\mathrm{v}}$ acts like a surcharge on the top surface of the wedges located on both sides of the tunnel. The corresponding lateral pressure on the sides of the tunnel can be 
computed by means of Coulomb's theory with the assumption that the sides of the tunnel are simple retaining walls the backfill of which carries a uniformly distributed surcharge, $\sigma_{\mathrm{v}}$ per unit of area.

The pressure which acts on the roof of the tunnel is transferred to the sand beneath the bottom of the tunnel through the footings of the vertical posts. The remainder of the weight of the sand located above the roof is transferred by shearing stresses to the sand adjacent to the tunnel. Hence the distribution of the vertical pressure on a horizontal section through the bottom of the tunnel must be similar to the distribution shown in Fig.1(c).

If a tunnel is located at a great depth below the surface the arching effect does not extend beyond a certain elevation $D_{1}$ above the roof of the tunnel. The sand located above this elevation, from the surface of the ground down to a depth $\mathrm{D}_{2}$, acts on the zone of arching like a simple surcharge with an intensity $\gamma_{2}$ per unit of area. In this case, the pressure on the roof of the tunnel is determined by $c=0, q>0$ as shown

In follows;

$$
\sigma_{v}=\frac{\gamma B_{1}}{K \tan \phi}\left(1-e^{-K \tan \phi \frac{D_{1}}{B_{1}}}\right)+\gamma D_{2} e^{-k \tan \phi \frac{D_{1}}{B_{1}}}
$$

The angle of internal friction $\Phi$ for a sand is at least equal to $30^{\circ}$ and from experiments it has been found that the value $\mathrm{K}$ is at least equal to unity. If the roof of a deep tunnel yields, the height $\mathrm{D}_{1}$ of the zone of arching increases while the height $\mathrm{D}_{2}$ decreases. As soon as the height $\mathrm{D}_{1}$ becomes equal to about 20 per cent of the total depth $D_{1}+D_{2}$ the second term on the right-hand side of the preceding equation becomes negligible. The first term is smaller than $\gamma B_{1} / K \tan \phi$ for all values of $\mathrm{D}_{1}$. Hence the pressure per unit of area of a deep tunnel through dry sand does not exceed an upper limiting value, which is equal to

$$
\sigma_{v \infty}=\frac{\gamma B_{1}}{K \tan \phi}
$$

Although the arching does not extend to the surface of the ground.

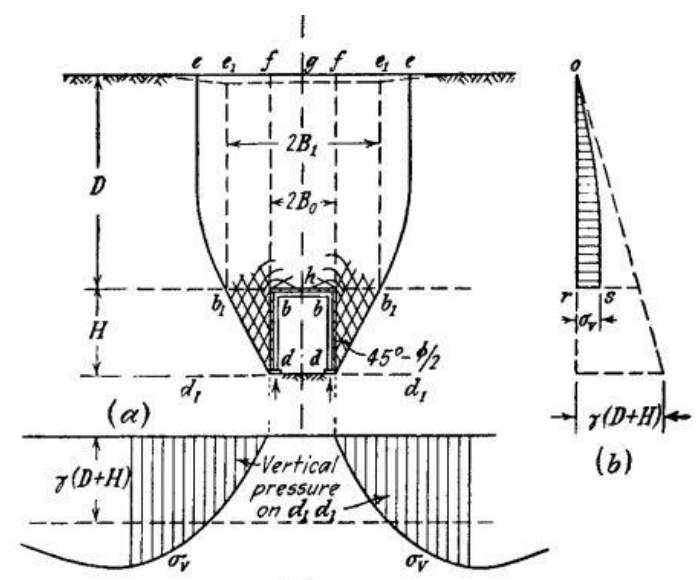

(c)

Fig. 1 (a) Flow of sand toward shallow tunnel at instant of failure of timbering

(b) Vertical unit pressure in sand above center line of tunnel plotted against depth

(c) Distribution of vertical pressure on horizontal section through bottom of tunnel

\subsection{Prediction of Settlement Due to Tunnel Excavation}

Schmidt observed, as reported by peck(1969), that the settlement curves resemble an error function of Gaussian possibility curve(Fig.2) described by the equation

$$
\mathrm{s}=S_{\max }\left[\exp \left(-\frac{x^{2}}{2 i^{2}}\right)\right]
$$

where $S_{\max }=$ maximum settlement over the crown

$$
x=\text { horizontal distance }
$$

$i=$ horizontal distance to inflection point 
The properties of the curve are related to tunnel depth $\mathrm{H}$ and diameter R. Peck presented a relationship between $H / R$ and $\mathrm{i} / \mathrm{R}$ for various soil types.

The relationship between settlement trough width $2 \mathrm{w}$ and $\mathrm{H} / \mathrm{R}$ for various soil types is given in Fig.3, as is the relationship between $\mathrm{H} / \mathrm{R}$ and $\mathrm{i} / \mathrm{R}$. The curves are used to estimate the differential deflection to be anticipated as a function of distance from the tunnel centerline, as well as the total trough width. It may be noted that the trough for soft clays is several times the width of that for hard clays or dry sands

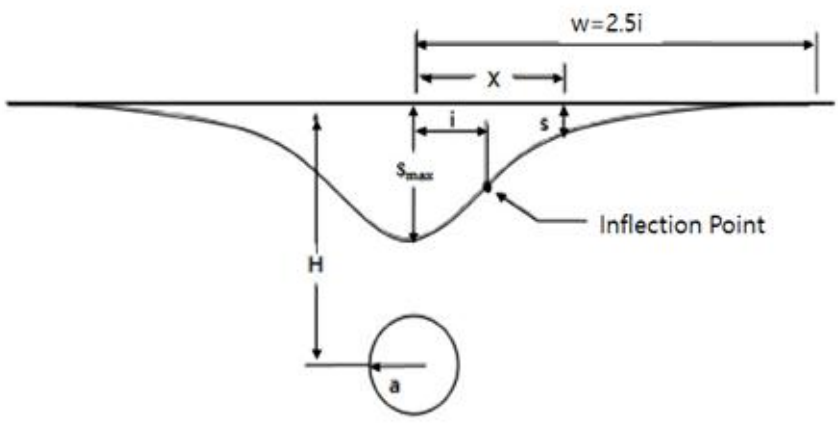

Fig. 2: Settlement trough characteristics

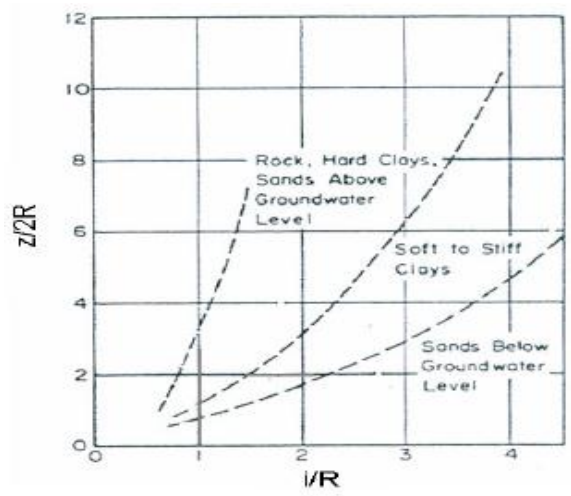

Fig. 3: Relationship between tunnel depth and diameter and settlement trough for various soil types

\section{Calibration Chamber Test}

\subsection{Outline of Calibration Chamber test}

The calibration chamber tests were conducted to investigate the effect of the surrounding ground according to the complex behavior of press-fitted steel pipes used for non-open cut method. The ratio of the soil depth/pipe diameter (H/D) and the number of press-fitted steel pipes were changed during the test. The ground constituting the embankment was constructed using standard Jumunjin sand as shown in Fig. 4. Table 1 shows the properties of the standard Jumunjin sand. The model was constructed with $2.0 \mathrm{~m}$ in length, $0.9 \mathrm{~m}$ in height and $0.6 \mathrm{~m}$ in width as shown in Fig. 5. Dyed sand was used to easily grasp the deformation of the ground during press-fitting steel pipes. The arrangement of the dyed sand was composed of three lines from the bottom of press-fitted steel pipes to the centre and top, and was formed at intervals of $50 \mathrm{~mm}$ from the top of the pipe.

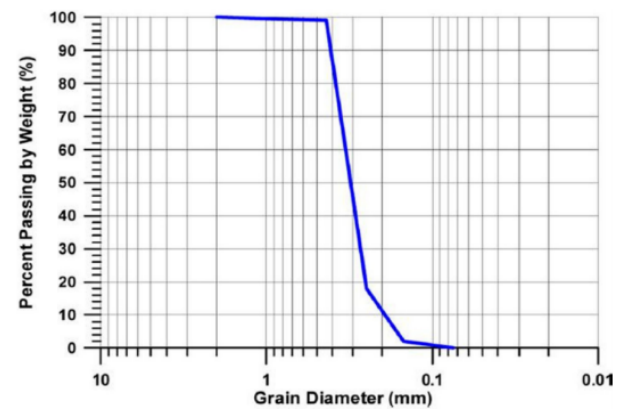

Fig. 4: Grading curve of standard sand

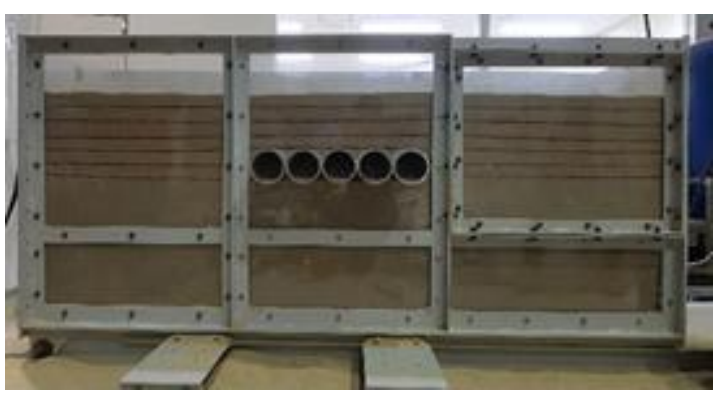

Fig. 5: Calibration chamber test model

Table 1: Data on properties of standard Jumunjin sand

\begin{tabular}{|c|c|c|c|c|c|c|}
\hline $\mathrm{G}_{\mathrm{s}}$ & $\mathrm{D}_{10}$ & $\mathrm{D}_{30}$ & $\mathrm{D}_{60}$ & $\mathrm{C}_{\mathrm{u}}$ & $\mathrm{C}_{\mathrm{g}}$ & $\mathrm{USCS}$ \\
\hline 2.62 & 0.27 & 0.35 & 0.5 & 1.82 & 0.88 & $\mathrm{SP}$ \\
\hline
\end{tabular}


The ratio of 1:20 was used to reduce the soil depth of $4 \mathrm{~m}$ to $200 \mathrm{~mm}$, and steel pipes with diameters of 100 $\mathrm{mm}, 67 \mathrm{~mm}$ and $40 \mathrm{~mm}$ were used. As shown in Table II, to investigate the complex behavior of press-fitted steel pipes used for non-open cut method, three cases were tested with H/D values of 2, 3 and 5.

The experimental method was as follows: internal excavation was performed after one steel pipe was pressfitted, and vertical displacement of the upper ground was measured. Then when the three and five steel pipes were press-fitted, the measurement was carried out gradually in the same way.

Table II: Experimental Condition

\begin{tabular}{|c|c|c|c|}
\hline & Soil depth $(\mathrm{H})$ & Pipe diameter $(\mathrm{D})$ & Soil depth/pipe diameter $(\mathrm{H} / \mathrm{D})$ \\
\hline \multirow{3}{*}{ Case1 } & \multirow{3}{*}{$200 \mathrm{~mm}$} & $100 \mathrm{~mm}$ & 2 \\
\cline { 1 - 1 } Case2 & $67 \mathrm{~mm}$ & 3 \\
\cline { 1 - 1 } & & $40 \mathrm{~mm}$ & 5 \\
\hline Case3 & & & 5 \\
\cline { 3 - 4 } & &
\end{tabular}

\subsection{The Results of Calibration Chamber Test}

The settlements of the upper ground were analyzed in order to understand ground deformation characteristics according to the complex behavior of press-fitted steel pipes. The result of settlement for each press-fitted steel pipe in the calibration chamber test is shown in Fig. 6 8. Fig. 6 shows H/D = 2, and Fig. 7 in turn is $H / D=3$. Fig. 8 shows the result of $H / D=5$. It is found that the similar settlement occurs to the failure surface according to Rankine 's active earth pressure theory.

In the case of $H / D=2$, the settlement increased 3 times when three steel pipes were press-fitted than one steel pipe, and the settlement increased by 1.3 times at five steel pipes than three steel pipes.

In the case of $\mathrm{H} / \mathrm{D}=3$, the settlement increased by 2.4 times when three steel pipes were press-fitted than one steel pipe, and the settlement increased by 1.25 times at five steel pipes than three steel pipes.

In the case of $\mathrm{H} / \mathrm{D}=5$, the settlement increased by 1.75 times when three steel pipes were press-fitted than one steel pipe, and the settlement increased by 1.23 times at five steel pipes than three steel pipes.

However, as the number of steel pipes indentations increases, the increase in settlement decreases. The lower the H/D ratio, the more the number of press-fitted steel pipes and settlements were proportional. The higher the H/D ratio, the less the correlation between the number of press-fitted steel pipes and settlements (Fig. 9). Also, as the number of press-fitted steel pipes increases, settlements occurred in proportion to the increase of the steel pipe diameter, and the smaller the number of press-fitted steel pipes, the less the correlation between the steel pipe diameter and settlements (Fig. 10).

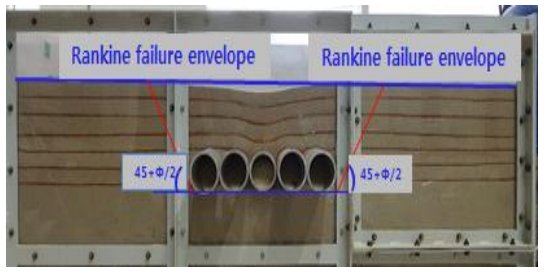

(a) 1 press-fitted steel pipe

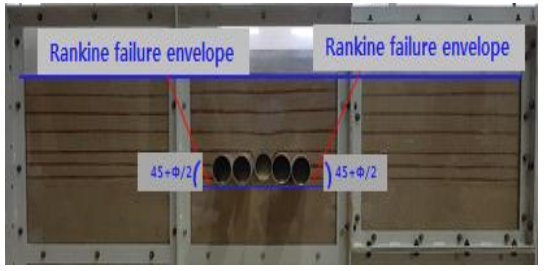

(a) 1 press-fitted steel pipe

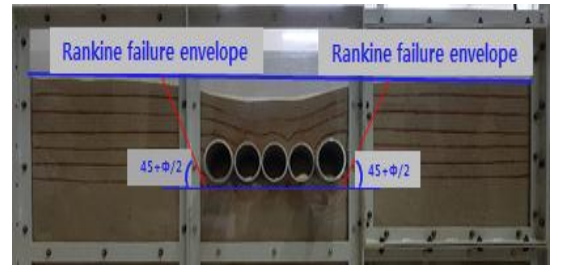

(b) 3 press-fitted steel pipes

Fig. 6: The results of test when $\mathrm{H} / \mathrm{D}=2$

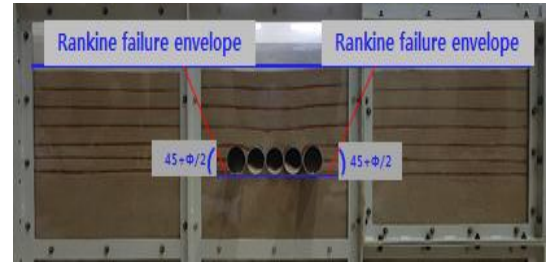

(b) 3 press-fitted steel pipes

Fig. 7: The results of test when $H / D=3$

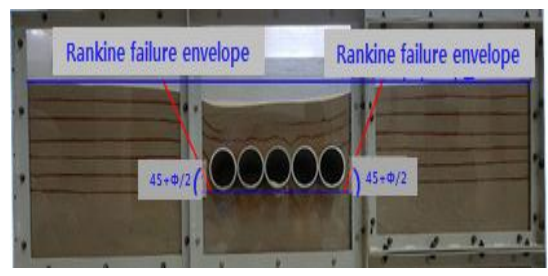

(c) 5 press-fitted steel pipes

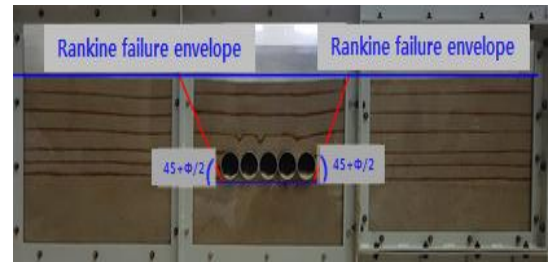

(c) 5 press-fitted steel pipes 


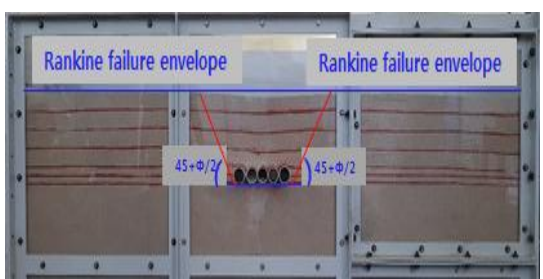

(a) 1 press-fitted steel pipe

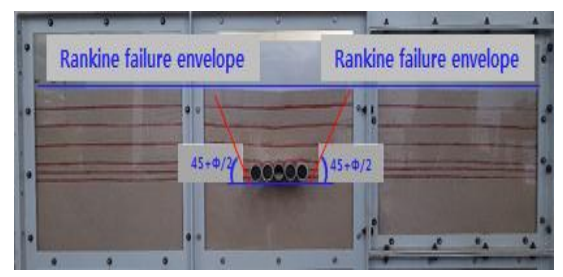

(b) 3 press-fitted steel pipes

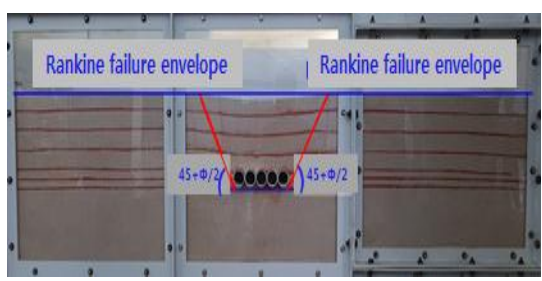

(c) 5 press-fitted steel pipes

Fig. 8: The results of test when $\mathrm{H} / \mathrm{D}=5$

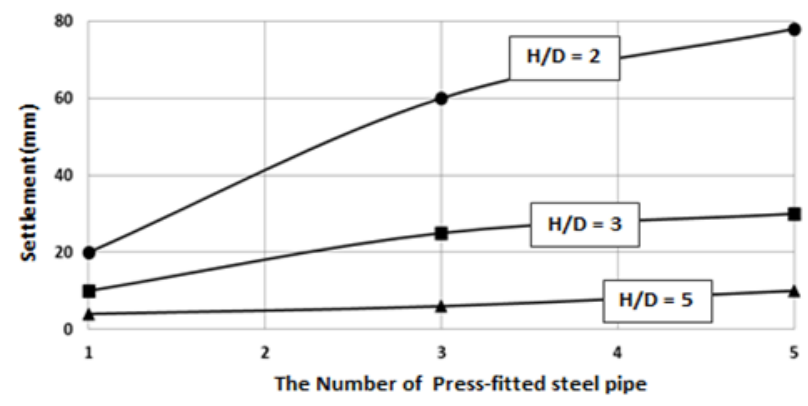

Fig. 9: Settlement according to the number of steel pipes

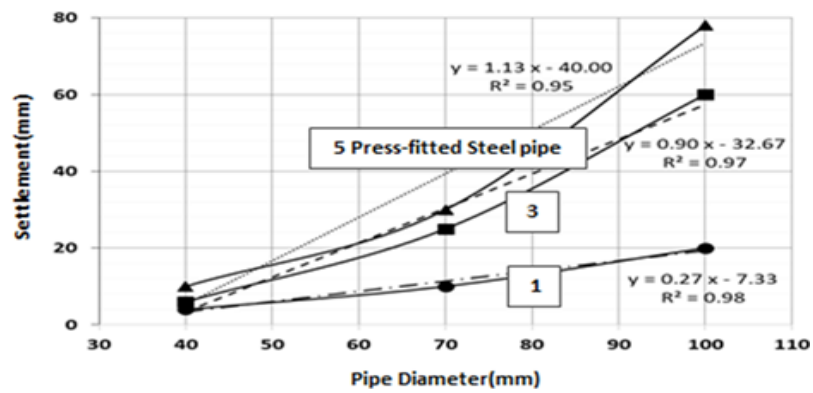

Fig. 10: Settlement according to pipe diameter

\section{Conclusion}

Underground structure construction using the non-open cut method under railway or highway has recently expanded in popularity. However, unsafe situations have also increased as non-open cut construction has become more popular.

The calibration chamber tests were conducted to study ground deformation characteristics according to the complex behavior of press-fitted steel pipes used for non-open cut method. The results from tests showed that as the number of steel pipe indentations increases, the increase in settlement decreases. The lower the H/D ratio, the more the number of press-fitted steel pipes and settlements were proportional. The higher the H/D ratio, the less the correlation between the number of press-fitted steel pipes and settlements. Also, as the number of press-fitted steel pipes increases, settlements occurred in proportion to the increase of the steel pipe diameter, and the smaller the number of press-fitted steel pipes, the less the correlation between the steel pipe diameter and settlements.

Therefore, the settlement due to the complex behavior of press-fitted steel pipes should be considered when using non-open cut method.

\section{References}

[1] Eun. K.Y., Shin. M.H., and Kim. J.H., "The analysis of Ground Behavior on the Crossing Construction Under Railroad Using Field Measurement," Journal of the Korea Society for railway, Vol. 5, No. 2, pp. 83-89, 2001.

[2] Roh. J.M., "Numerical Analysis of Crossing Tunnel Using Roof Panel Shield Method," Master thesis, Dept. Civil and Environmental system Eng., University of Incheon., South Korea, 2006.

[3] Choi. S.W., Park. Y.T., Chang. S.H., Bae. G.J., Lee. K.T., Baek. Y.K., "A numerical study on the three-dimensional ground movement by the trenchless construction method of concrete box by a square steel pipe supporting system," Journal of Korean Tunnelling and Underground Space Association, Vol. 14, No. 5, pp.469-484, 2012.

[4] Eum. K.Y., Choi. C.Y., Cheon. J.Y., "Analysis of Heaving and Settlement Test of Scale Model Depending on Shape of the Pipe during Pipe Roof Excavation," Journal of Korean Geosynthetics Society, Vol. 9, No. 4, pp. 485-501, 2010

[5] Kim. J.Y., Park. S.B., Kim. M.N., Cho. K.H., "A Study on the characteristics of stress release zone according to diameter of steel pipes by non-open cut method," presented at the IRES, Istanbul, Turkey, June 22-23, 2017.

[6] Terzaghi, K., Theoretical Soil Mechanics, John Wiley \& Sons, 1948.

[7] Peck. R. B., "Deep excavations and tunneling in soft ground," in Proc. 7th Int'l Conf. on Soil Mech. and Foun. Eng., Mexico City, State-of-the-Art, pp. 225-290, 1969. 